\title{
Time allocation within the Family: Welfare implications of life in a couple
}

\author{
Hélène COUPRIE*
}

February 17, 2006

(Revised version)

Abstract: This paper analyses the household decision-making process leading to the allocation of time and consumption within the family. We estimate, on the British Household Panel Survey, a collective model of leisure demand generalised to the production of a household public good. The sharing rule is identified by using an original parametric framework based on the change of family status: from single-living to couple or from couple to single-living. Womens' ratios of private household expenditures are $40 \%$ on average. The level of intra-household inequality appears highly dependent on the intrahousehold wage gap. Omitting household production in the model would overestimate the ratio by 7 percentage points on average.

Keywords: Household production, Collective model, Sharing rule.

J.E.L. Classification J22, D13, D63, C33

\footnotetext{
*Université Toulouse I, GREMAQ, Manufacture des Tabacs, bât. F, 21 Allée de Brienne, 31000 Toulouse, France, Phone +33 (0)561 1286 84, Fax +33 (0)5 612255 63, e-mail: helene.couprie@univ-tlse1.fr. This paper was partly written in ISER, University of Essex, CAM, University of Copenhagen, and during a postdoctoral year in CIRPEE, Université Laval. It is also part of my PhD defended in GREQAM, Université de la Méditerranée. Financial support from the Marie Curie Fellowship Association, the CIRPEE and the Canada Research Chair in Social Policies and Human Resources are gratefully aknowledged. The BHPS data were made available through the Data Archive, University of Essex. I address special thanks to John Ermisch, Martin Browning, Mette Erjnaes, Bernard Fortin, Bo Honoré, Nicolas Gravel, anonymous referees and the members of my $\mathrm{PhD}$ committee for stimulating research comments.
} 


\section{Introduction}

Because most of income variables are collected at the household level, welfare evaluations of economic policy generally focus on between households inequality. If individuals are the ultimate object of concern for economic policy, then the level of intra-household inequality and its economic determinants should be evaluated. Haddad and Kanbur (1990) find that between individuals inequality may be understated by $30 \%$ or more when neglecting intra-household inequality in Philippine. Understanding the effect of economic variables on intra-household inequality is also important for an appropriate design of the policy (e.g. targeting a specific household member, conditioning on the marital status...). The standard "unitary" practice considers the household as a unique decision-making unit. In this case, the policy instrument appears neutral on the distribution of well-being within the household. "Collective" models may have different implications. This growing body of the literature takes into account the plurality of decision-makers within the household (Chiappori, 1988; Chiappori, 1992; Browning and Chiappori, 1998; Dauphin and Fortin, 2001; Chiappori and Ekeland, 2002a). The collective framework relies on a "minimalist" assumption of Pareto-efficiency of household's outcome. The main consequence is that a change in prices may directly affect

the balance of powers within the family and the level of intra-household inequality. Household behavioural analysis becomes richer because a negociation effect is added to the standard substitution and income effects. One interesting implication is that if individual incomes enter into the bargaining process, then the income-pooling property may not be satisfied. Hence, a targeted transfer may lead to different household behavioural outcomes depending on who receives the transfer within the family. From an empirical viewpoint, collective models usually appear not to be rejected against the unitary model (Fortin and Lacroix, 1997; Chiappori, Fortin and Lacroix, 2002). Income pooling in particular appears rejected by the data (e.g. Lundberg, Pollak and Wales, 1997). 
The collective approach has great potential for studying individual-based welfare analysis. A collective outcome may be viewed as a decentralised choice of household's members conditional on an implicit distribution of income within the household, which is denoted the sharing rule. This function of prices and incomes is intrinsically related to the distribution of individuals' well-being within the family and may be directly interpreted in terms of intra-household inequality. However, it cannot be directly observed and may be identified at the price of some behavioural assumptions. Indirect identification of the sharing rule is possible from a non-parametric or a parametric perspective.

Chiappori (1992) first showed that, in the egoistic case, the observation of individual labour supply data and household consumption allows non-parametric identification of the sharing rule up to a constant. This result was recently extended to altruism and public consumption (Chiappori, Blundell and Meghir, 2002; Chiappori and Ekeland, 2002b). Hence, non-parametric identification of the sharing rule, which is 'the ideal case', at best permits analysis of variations in individuals' welfare related to changes in exogenous variables. On the other hand, parametric identification of the sharing rule relies on stronger assumptions but allows richer welfare analysis by allowing direct welfare comparisons between individuals. As a result, 'collectively-based equivalence scales' can be constructed (Browning, Chiappori and Lewbel, 2003) and individualbased cardinal inequality criteria can be computed (Lise and Seitz, 2004). Parametric identification of the sharing rule also allows the effect of variables that are present both in preferences and in the sharing rule, such as age, children, marital status, etc. to be disentangled. In the literature, parametric identification of the sharing rule has been obtained under strong assumptions to date, such as identity of preferences or identity of the marginal utility of consumption between individuals of different marital status. It is very likely that an individual living single will present different preferences than an individual living in a couple. In a cross-section analysis, these differences are more likely if individuals are endogenously selected into marriage. 
In both the parametric and non-parametric cases, identification of the sharing rule usually relies on the presence of an 'assignable' good, i.e. a private good whose consumption can be individually observed. Individual non-labour time is usually taken as an assignable good, ignoring household production. This is very likely to bias the evaluation of intra-household inequality for two reasons. First, as time spent at housework is unequally shared by gender, female's share of welfare is likely to be biased upward. Second, positive externalities of time consumption within the family are basically ignored. This is especially true in the presence of children. Collective modelling in the presence of household production raises several difficulties as the level of production is unobservable. Apps and Rees (1997) and Chiappori (1997) present a model in which the household good is privately allocated between household members. They show that the sharing rule remains identifiable if the domestic good is marketable or if the domestic production function presents constant returns to scale. Aronsson, Daunfeldt and Wikström (2001) implement such an estimation based on a match between a time-use survey and a labour force survey. Still, the private household good case does not allow to control for positive externalities due to time consumption.

The aim of this paper is to estimate the sharing rule of British couples. Compared to the existing literature, it presents three main advantages. First, identification of the sharing rule is based on the observation of pure leisure time, i.e. total time minus time spent on the labour market or performing housework. It requires that the household good is public and its consumption separable from other individual consumptions. This approach tends to reconcile the collective model to the presence of children, whose welfare can be modelled as a public good for their parents. Second, the panel identification, in first difference, controls for differences in females' preferences across cohabitational status explained by some fixed unobserved heterogeneity term. Third, the problem of matching data from time-use and labour force surveys is not an issue here because the British Household Panel Survey has the great advantage of simultaneously containing information about time spent both at housework and on the labour market. The re- 
sults show that the sharing rule is nearly $40 \%$ on average for working women. The bias resulting from ignoring household production is also evaluated.

The outline of the paper is as follows: Section 2 develops the theoretical model and some general aspects of identification of the sharing rule. Then we describe the econometric panel data specification in Section 3. Section 4 presents the results and Section 5 concludes.

\section{A model of the allocation of time within the family}

The allocation of time within the family is modelled with a collective model of labour supply, extended to include the production of a household public good. We first present the model, then the basics for identification of the sharing rule.

\subsection{A conditional collective model of leisure demand for couples}

We focus on the time allocation decision of couples with or without children. Spouses or parents share bargaining power, whereas children do not have any. Two types of goods can be consumed: a Hicksian composite good $C$ and a public domestic good $D$, which is produced with spouses' inputs of time. Individual total time, $T$, can be allocated to the production of the domestic good, $t$, sold on the labour market, $H$, or directly consumed as leisure, $L$. The hourly wage is denoted by $w$ and $y$ is non-labour income. $F$ is full income, namely the income an individual would receive if she spent all available time working on the labour market: $F=w \mathrm{~T}+y$. In the following, we denote wives' and husbands' variables with the indices $f$ and $m$ when in a couple, and use the superscript $s$ for a single woman.

An individual $i$ has a preference ordering over household goods and time consumptions represented by the following utility function: $U_{i}\left(C_{i}, L_{i}, D\right)$. She cares about her own leisure $L_{i}$ and goods consumption $C_{i}$, but not about those of her husband. This framework generalises to Beckerian caring preferences (Becker, 1981). Here, the pres- 
ence of a household's public domestic good is the way to control for the presence of intra-household externalities in the consumption of non-labour time. There are greater chances that the externalities of family life play a role via everyday housework (preparing meals, cleaning, etc.) or child-care activities than via time spent on pure leisure, which is likely to involve less interaction. ${ }^{1}$

A major assumption in this framework is weak separability of the domestic public good and private goods in the utility function. The marginal rate of substitution between consumption and pure leisure is not affected by the level of public consumption. This means that public consumption will change the consumption-leisure trade-off only via an income effect. Such an assumption seems unavoidable in a context in which the public good is conceptual and unobserved. ${ }^{2}$ Separability imposes that:

$$
U_{f}\left(C_{f}, L_{f}, D\right)=W_{f}\left(u_{f}\left(C_{f}, L_{f}\right), D\right)
$$

where $u$ is the individual's sub-utility from private goods consumption. The individual subscript was omitted for sake of simplicity. There is no need for any market for the domestic good. If one exists, this market must be complete in order to prevent the household from making a profit by selling the internally-produced domestic good. The household's allocation is assumed Pareto-optimal, which complies with the central assumption of collective models. Conditional on public expenditures, the allocation of

\footnotetext{
${ }^{1}$ It can be argued that you increase your utility more by playing tennis with your spouse than with friends. You may also get less utility from watching TV with your spouse because your preferences over the programs differ, and vice versa. My claim is that pure leisure interactions should be relatively weak compared to housework or child-rearing activities.

${ }^{2}$ One could think avoiding the separability assumption by predicting the quantity of domestic good with a specific parametric shape for household technology. If reliable, this prediction would only obtain up to an unknown scaling parameter.
} 
private expenditures is Pareto-optimal and solves the following program:

$$
\begin{aligned}
& \operatorname{Max}_{C_{f}, C_{m}, L_{f}, L_{m}} \mu(.) u_{f}\left(C_{f}, L_{f}\right)+(1-\mu(.)) u_{m}\left(C_{m}, L_{m}\right) \\
& \text { st. }\left\{\begin{array}{l}
C_{f}+C_{m}+w_{f} L_{f}+w_{m} L_{m} \leq F_{f}+F_{m}-G \\
\widetilde{\mathrm{T}}_{j}=L_{j}+H_{j}
\end{array}\right. \\
& \text { with } \widetilde{\mathrm{T}}_{j}=\mathrm{T}-t_{j}, j=f, m,
\end{aligned}
$$

where $G$ represents the household's public expenditures. Any point on the Pareto frontier can be obtained as a solution to program $(P)$ for some well-chosen $\mu($.$) . In$ general, $\mu$ can be a function of prices, incomes, individual heterogeneity or distribution factors. ${ }^{3}$ If $\mu$ is fixed then the model collapses to a unitary one.

In a decentralised fashion, we obtain that each individual maximises her individual sub-utility, given the conditional sharing rule $\phi$ :

$$
\left\{\begin{array}{l}
M A X_{C_{j} L_{j}} \quad u_{j}\left(C_{j}, L_{j}\right) \\
\text { s.t. } \quad C_{j}+w_{j} L_{j}=\phi_{j}(.), j=f, m,
\end{array}\right.
$$

where $\phi_{j}$ is the sharing rule, i.e. the proportion of private expenditures (total full income minus public expenditures) going to individual $j$ within the family: $\phi_{f}+\phi_{m}=$ $F_{f}+F_{m}-G$. Compared to the unconditional approach, the sharing rule in this context depends on $G$, the amount of public expenditures. It naturally also depends on wages and non-labour incomes. The separability assumption allows the household's behaviour to be viewed as a two-step budgeting process. In the first step, public consumption is chosen and, in the second step, good and pure leisure consumptions are decided. If we restrict ourselves to the conditional case, nothing can guarantee the efficiency of the choice of public good consumption. If $G$ is efficiently chosen, then the conditional sharing rule in the separable case collapses to the unconditional case. Another implication of the conditional approach is that we have to carefully take into account the simultaneity of public and private expenditures in the empirical analysis. Public

\footnotetext{
${ }^{3}$ They are defined as covariates which are uncorrelated with individual preferences but which shift the balance of bargaining powers (e.g. sex-ratio, divorce legislation, etc.).
} 
expenditures correspond to $G=w_{f} t_{f}+w_{m} t_{m}$ for women in a couple ${ }^{4}$ and are observed in the data.

In principle, the sharing rule $\phi$ can be used as a tool to analyse intra-household inequality issues. The problem is that it is unobserved. However, it can be identified by observing household demand.

\subsection{Parametric identification of the sharing rule}

Using leisure consumption data of both partners in a couple, the intra-household distribution of income can be identified up to a constant. Chiappori (1992) argues that welfare evaluation of a reform remains possible in this case. Nevertheless, direct comparisons of welfare levels would be possible if such a constant were to be estimated. As a consequence, we would know which member of the family is better off. Moreover, estimating the determinants of the distribution of welfare inside the family would also become possible. We here present the basics of the sharing rule identification mechanism. For simplicity, we present a case ignoring public consumption and individual heterogeneity. ${ }^{5}$

A closed-form leisure demand model for women in couples is

$$
L_{f}=L_{f}\left(w_{f}, w_{m}, y_{f}, y_{m} ; \theta\right)
$$

It depends on both spouses' wages, $w$, non-labour income, $y$, and on a set of parameters, $\theta$. Imposing collective behaviour, the structural model of leisure demand can be

\footnotetext{
${ }^{4}$ We here follow the usual approach in collective models, which consists of omitting non-labour inputs in household production (Apps and Rees, 1997, Chiappori, 1997, Aronsson and al., 2002). Even if the Hicksian composite good theorem applies, this omission could involve measurement errors in public expenditures that are not controlled for in our framework.

${ }^{5}$ Incorporating public consumption into our framework only requires us to express full incomes minus public expenditures. The sharing rule becomes conditional on public expenditures. The full case is described in Section 3.
} 
rewritten in terms of a Marshallian demand and the sharing rule

$$
L_{f}=M_{f}\left(w_{f}, \phi_{f}\left(w_{f}, w_{m}, y_{f}, y_{m} ; \rho\right) ; \beta\right)
$$

Given females' income shares, $\phi_{f}$, the leisure demand equation is a Marshallian demand, denoted by $M_{f}$. The parameters of the Marshallian demand are denoted $\beta$. The sharing rule, $\phi_{f}$, depends on wage rates, non-labour incomes (and possibly distribution factors). The parameters and the constant of the sharing rule are in the $\rho$ vector. There is no error term in the sharing rule. ${ }^{6}$

Assuming that the parameters of the closed-form model, $\theta$, are identified, the parameters of the structural model $(\beta, \rho)$ will be parametrically identified in the presence of a unique relationship between the vectors $(\beta, \rho)$ and $\theta$, which is not generally true. Indeed, the dimension of the set of parameters $(\beta, \rho)$ is greater than the dimension of the set $\theta$, so that the parameters of the sharing rule $\rho$ are unidentified without further information.

In order to deal with this identification problem, Chiappori, Fortin and Lacroix (2002) estimate, jointly with Equation (2.2), a similar equation for males' behaviour, yielding another set of parameters of the same dimension as $\theta$. Overidentifying restrictions, related to the sharing rule, then hold: $\phi_{f}=F_{f}+F_{m}-\phi_{m}$. It is well known that the derivatives can be non-parametrically recovered in this case.

In the parametric case, females' Marshallian demands are assumed to be the same across marital statuses. This is possible if preferences are identical regardless of marital status. This type of assumption has been used so far in cross-section data (Laisney, 2002; Browning, Chiappori and Lewbel, 2003; Lise and Seitz, 2004; Vermeulen, 2005). It is a strong assumption given that women living single and in a couple may present different preferences for leisure not controlled for by observed heterogeneity variables. In panel data, this assumption is more acceptable because we deal with the same

\footnotetext{
${ }^{6}$ To our knowledge, it was the case in all empirical implementations of a collective model (e.g. Chiappori and al., 2002). Clearly, this kind of assumption should be relaxed in further research.
} 
individuals, which avoids, up to a certain point, the selection bias in preferences for leisure. In this case, identification is obtained via the change of cohabitational status. In fact, even if the assumption of identical marginal utilities of consumption is more plausible in the panel case, it is still arguable that marital status itself generates a change in individuals' preferences, in which case the stability assumption would be violated. Aside from a possible direct change in the structure of preferences, which we cannot really exclude, this change in preferences can possibly be caused by the presence of externalities of consumption of pure leisure not controlled for in our framework. These externalities should also be identified. The problem is that single-living women typically do not experience any of these externalities as they do not have a spouse, so that we cannot rely on them to give us an additional information on this point. In this framework, externalities in couples' consumption only comes from the public nature of household production, and this generates positive externalities of consumption in the time spouses spent at housework. However, we cannot exclude that this way of controlling externalities can be rough compared to what could be done (see for example Fong and Zang, 2001).

Let us denote by $M$ the female's Marshallian demand for leisure when she is single. This function is the same across cohabitational statuses.

$$
L_{f}^{s}=M_{f}\left(w_{f}^{s}, F_{f}^{s} ; \beta\right)
$$

with $\beta$ being the set of parameters and $s$ the subscript for single women. The $\widehat{\beta}$ parameters are estimated from the sample of single-living women and can be plugged into Model (2.3). The $\theta$ parameters are identified from the closed-form model on women in couples' leisure demand. So the dimension of $(\beta, \theta)$ could be greater than the dimension of $\rho$ alone, making identification possible.

More precisely, the sharing rule can be obtained by inverting females' Marshallian demand for leisure with respect to full income. Assuming monotonicity of the income effect and denoting $M^{-1}$ the inverse of the $M_{f}$ function with respect to $F$, we get a 
structural relationship between the parameters $\theta, \beta$ and the unknown parameters of the sharing rule $\rho$ :

$$
\phi_{f}\left(w_{f}, w_{m}, y_{f}, y_{m} ; \rho\right)=M^{-1}\left(L_{f}\left(w_{f}, w_{m}, y_{f}, y_{m} ; \theta\right), w_{f} ; \beta\right) .
$$

For this kind of identification, it is clear that the functional choice of the Marshallian demand and the sharing rule matters. In the linear case, the $\rho$-parameters are easily recovered as a function of $\theta$ and $\beta$. In the nonlinear case, only very specific parametric shapes of the sharing rule and of the inverse leisure demand will ensure identification of $\rho$. The weakness of this method is that identification remains parametric. Its strength is that it allows recovering the constant of the sharing rule and disentangling the effects of the heterogeneity variables $Z$ in preferences and negotiation effects, which is an important empirical aspect.

To summarise, the keys to the parametric identification of the sharing rule using data for single individuals are the following. First, the inverse of the Engel curve of single individuals' leisure demand must exist and be unique. Second, the sharing rule $\phi$ must be parameterized such that $\rho=f(\theta, \beta)$. Third, individual preferences must be stable across marital status. Finally, we should notice that adding the same identification process with a male leisure demand equation would strengthen identification by adding an over-identification restriction. However, it may appear difficult to follow both members of a couple changing their cohabitation status over time.

\section{Implementation on the BHPS}

\subsection{Data}

The British Household Panel Survey contains a full set of information about households and their members from 1992 to 2000. Not only labour supply behaviour is reported (usual weekly hours of paid work, labour earnings, and non-labour earnings), but also time spent on housework activities during the week. Even if such a response is subjective, it provides an approximation to the share of time allocated to producing the 
domestic good. The time-use information, based on individuals' statements, is probably less reliable than in an objective time-use survey. Measurement errors could appear if individuals do not have a homogeneous definition of housework. But, after all, labourmarket hours of work information also comes from individual statements and could be subject to the same evaluation problems. This being so, at least we do not have to venture into merging two different data sources.

The sub-sample is composed of working women, single or living in a couple, with or without children, observed during at least two periods. The selection of two-earner couples and more generally working couples is necessary for the data to fit into the collective framework specified. This is because the theoretical framework only handles interior solutions. Even though participation bias is rarely controlled for in the collective literature, this issue is very important and we should bear in mind that our results remain conditional on labour market participation of both spouses. ${ }^{7}$

\section{[INSERT TABLE1]}

This constitutes a sample of 2585 observations of women living single and 7179 of women living in a couple, 2342 individuals overhall with an average of 4 time observations per individual. Descriptive statistics of the sub-sample are reported in Table 1. Time spent at housework by men is particularly low compared to time spent by women: 5 hours a week for men versus 15 for women. For the empirical analysis, the real hourly wage is calculated by dividing the usual net monthly wage by the usual hours of work per month (including overtime) and by the price index.

Potential non-ignorable missing data bias due to attrition is not controlled. Crouchley, Bradler and Oskrochi (2005) evaluate that such a potential bias may exist when jointly modelling employment and wages. According to their analysis, missing data appear more frequently in area with high unemployment rate and may be attributed

\footnotetext{
${ }^{7}$ Generalisations of the collective model to non-participants are proposed by Donni (2003) and Blundell, Chiappori, Magnac and Meghir (2001). In both cases household production is not included.
} 
to job search mobility. Potential links between attrition in the BHPS, employment and family formation or dissolution are still unknown and may bias our results.

\subsection{Specification}

We assume that women's conditional demands for consumption and leisure follow a Linear Expenditure System (LES). The expenditure function for woman $i$ at time $t$ is: ${ }^{8}$

$$
c\left(w_{f}, u_{f}\right)=\gamma+w_{f} \alpha+u_{f} w_{f}^{\beta},
$$

with $w_{f}$ the female's wage rate and $u_{f}$ her individual sub-utility level, varying for each individual at each time period. The parameters are scalar. $\alpha$ stands for the subsistence level of leisure, $\gamma$ stands for the subsistence level of consumption. $\beta$ must be such that $0<\beta<1$ to ensure concavity of the expenditure function and rationality of individual behaviour. At the optimum, the total cost to a woman living single corresponds to her private expenditure $E_{f}$, which equals full income minus the opportunity cost of housework time: $E_{f}=F_{f}-w_{f} t_{f}$. Given the decentralisation property of the collective model (see program $\left(\mathrm{P}^{\prime}\right)$ ), a woman in a couple will spend her share of private household expenditures according to the conditional sharing rule $\phi$ :

$$
c\left(w_{f}, u_{f}\right)=\left\{\begin{array}{l}
E_{f} \text { if single } \\
\phi_{f} \text { if in couple. }
\end{array}\right.
$$

Solving for $u_{f}$ and applying the Roy identity yields the following demands for leisure:

$$
L_{f}=\left\{\begin{array}{l}
(1-\beta) \alpha-w_{f}^{-1} \gamma \beta+E_{f} w_{f}^{-1} \beta \text { if single } \\
(1-\beta) \alpha-w_{f}^{-1} \gamma \beta+\phi w_{f}^{-1} \beta \text { if in a couple }
\end{array}\right.
$$

When $\phi$ is fixed, these demands correspond to standard Marshallian demand functions. Denoting by a dummy variable the cohabitation status: $d=1$ if a woman is in a couple and 0 if she is not, the demand for leisure of a woman, whatever her family status, is:

$$
L_{f}=\beta d \phi w_{f}^{-1}-\beta \gamma w_{f}^{-1}+\beta(1-d) E_{f} w_{f}^{-1}+\alpha(1-\beta) .
$$

\footnotetext{
${ }^{8}$ For sake of simplicity in the notation, individual and time subscripts are omitted in this section.
} 
In general, the share of household income allocated to the woman's own private consumption $\phi$ depends on prices, incomes, distribution factors and preferences. Here, it is also conditional on households' total public expenditures $G$. The sharing rule is simply taken as linear with respect to wages, non-labour incomes, and public expenditures:

$$
\phi=\rho_{1}+\rho_{2} w_{f}+\rho_{3} w_{m}+\rho_{4} y_{f}+\rho_{5} y_{m}+\rho_{6} G .
$$

Substituting the sharing rule (3.5) into the leisure demand Equation (3.4), adding an error term and a fixed effect in preferences for leisure, we get an extended form for the leisure demand equation, linear with respect to the parameters.

\subsection{Estimation}

The demand for leisure equation of woman $i$ at time $t$ can be reduced to

$$
L_{f_{i t}}=Z_{i t}^{\prime} \theta+\mu_{i}+e_{i t}
$$

where $i=1, \ldots, N$ and $t=1, \ldots, T$. The vector of parameters $\theta$ is $8 \times 1, Z_{i t}^{\prime}$ is a $1 \times 8$ vector of explanatory variables which are transformations of the wages, expenditures and cohabitational status variables. The $Z^{\prime}$ matrix contains $N T$ rows and is the concatenation of 8 column vectors:

$$
Z=\left(d w_{f}^{-1}, d, d w_{m} w_{f}^{-1}, d y_{f} w_{f}^{-1}, d y_{m} w_{f}^{-1}, d G w_{f}^{-1}, w_{f}^{-1},(1-d) E_{f} w_{f}^{-1}\right)
$$

$e_{i t}$ is an independent and identically distributed error term. It is likely that the fixed effect $\mu_{i}$ is correlated with covariates or the error term. For example, unobserved heterogeneity variables are likely to influence the decision-making process, they can also simultaneously determine the individual hourly wage rate. These variables could also be correlated with the cohabitational status if the marriage market endogenously selected individuals with specific leisure preferences.

We can easily recover the structural parameters of preferences (3.4) and the sharing rule (3.5) from the closed form parameters $\theta$ in Equation (3.6). Preference parameters 
are given by

$$
\beta=\theta_{8}, \alpha_{i}=\frac{\mu_{i}}{1-\theta_{8}} \text { and } \gamma=-\frac{\theta_{7}}{\theta_{8}},
$$

and the sharing rule parameters are given by

$$
\rho_{j}=\frac{\theta_{j}}{\theta_{8}}, \text { for } j=1, \ldots, 6 .
$$

The covariates, which are mainly wages and income variables, are very likely to be endogenous. In practice, households' consumption choices on the domestic good and leisure are simultaneous. As for income variables, public expenditures are endogenous and we need to control for this. In the separability case, endogeneity only comes from an income effect. Indeed, the choice of private and public expenditures is simultaneous so that private expenditures will depend on some unobservables correlated with leisure demand. Endogeneity can also come directly from the time allocation. Indeed, if one spends more time at housework, the time endowment to split between market work and leisure is shortened, so that total private expenditures will be reduced. Hence, the strict exogeneity assumption of these variables could be unreliable. On the other hand, the endogeneity of private and public expenditures can be controlled with timevarying instrumental variables, which are weak and could present a significant small sample bias, thus also be unreliable. This is why we assume predetermination of these variables. Arellano and Bond (1991) propose an estimator suitable for this kind of analysis. A comprehensive survey of empirical practice is Bond (2002).

More precisely, we make the conditional mean assumption: $E\left(e_{i t} / Z_{i t-k}\right)=0$, $\forall t, k \geq 0$. Present values of $Z$ can be correlated with future values of the error term but not vice versa. Taking the first difference of Equation (3.6) removes the fixed effect $\mu_{i}:$

$$
\Delta L_{i t}=\Delta Z_{i t}^{\prime} \theta+\Delta e_{i t}
$$

The predetermination assumption on $Z$ implies that $\Delta Z_{i t}$ is endogenous: $E\left(\Delta e_{i t} / \Delta Z_{i t}\right) \neq$ 0 . Lagged values of $Z$ are suitable instruments, especially the first lag $Z_{i t-1}$ which is strongly correlated with $\Delta Z_{i t}$ and uncorrelated with $\Delta e_{i t}$. First differencing generates 
autocorrelation of order 1 in the residual as $\Delta e_{i t}$ and $\Delta e_{i t-1}$ share the same $e_{i t-1}$ term. The estimator is a generalised method of moments estimator which uses, for each time period, the orthogonality condition between the instruments (lagged values of variables) and the error term. The instrumental matrix conforms to Arellano and Bond (1991).

Predetermination of the $Z$ variables remains a strong assumption as it requires that past wages and incomes do not influence present leisure shocks. As specification tests, we can check the order or autocorrelation of the residual and the validity of the overidentifying restrictions. If contemporaneous correlation is present: $E\left(e_{i t} / Z_{i t}\right) \neq 0$, the first lag cannot be introduced in the instrumental matrix because it is no more orthogonal to $\Delta e_{i t}$. Time spent at housework is simultaneously chosen with leisure time. As a consequence, it is probable that the orthogonality condition does not hold for first lagged public expenditures or for private expenditures. A difference Hansen test could give information about the validity of this additional orthogonality condition. Finally, an optimal choice of the matrix of instruments requires a parsimonious choice of the number of lags in order to efficiently reduce the bias without reducing the degrees of freedom too much.

\subsection{Further identification issues: family status variables}

Family status covariates, such as the number of children or the decision to get married, can be broken down into two effects: a preference and a sharing-rule effect. These variables were not included in the model because the identification of their effect on the sharing rule would only rely on within individuals variations of family status or number of children, interacted with within variations in the cohabitational status. As an example, only 15 individuals simultaneously experience a change in their cohabitational status and give birth to their first child. Moreover, the endogeneity of this type of variable is difficult to control, as we can only hope to find instruments weakly correlated to these variables. From this perspective, we keep the model in reduced form.

Most of the covariates in the model interact with the cohabitational dummy (see 
equation (3.7)). Identification relies on variations of the cohabitational dummy, $d$, within individuals. Nearly 300 individuals experience such a change which is a correct sample size. However change of cohabitational status is likely to be endogenous with respect to the time allocation process. Indeed, a shock in leisure time can increase or decrease the probability of future divorce. This is liable to bias our results. Controlling for the endogeneity of this dummy variable by using lagged values requires ignoring the potential support bias due to the linearity of the instrumental equation. Moreover it could increase the variance of the estimators and tend to make the evaluation less precise than in the exogenous case.

Difference-GMM estimator allows the presence of predetermined variables, we assume the following:

$$
E\left(e_{i t} / d_{i t}, d_{i t-k}\right)=0 \text { but } E\left(e_{i t-k} / d_{i t}\right) \neq 0, \forall k>0 .
$$

In this case, past marital status $d_{i t-1}$ is an adequate instrument to control for the endogeneity of $\Delta d_{i t}$. This assumption is consistent with a view of a sequential model of intra-family interactions in which past leisure shocks have consequences for future marital status (e.g. the time devoted to search for a partner on the marriage market was committed before the union occurred, or the chances of divorce are linked to past unemployment periods). Conversely, past changes in marital status would have no influence on current time allocation decisions, but current status does. An important aspect of the preceeding assumption is the absence of contemporaneous correlation between cohabitational status and leisure shock. Time allocation of period $t$ cannot influence the divorce or union of this period. This seems plausible because potential contemporaneous correlation is more probably related to individuals' (fixed) heterogeneity.

If predetermination does not hold, one can authorize contemporaneous correlation by using further lags as instruments. Second lag constitutes a weaker instrument than first lag, it also means that we lose more observations in the sample. Moreover it would 
imply the use of second lagged levels also for the spouses' variables. An Hansen test allows to check the validity of the orthogonality condition for the first lag.

\section{Results}

\subsection{Time allocation in unitary versus collective models}

There has been widespread evidence in recent years of the rejection of the unitary model in various contexts. Unitary household behaviour generates a testable incomepooling restriction. A unitary household would maximise a unique utility function for its members subject to a unique household budget constraint. As a consequence, household demand functions would depend on the sum of the income of all household members. In the time allocation problem, an interior solution would be a system of time use dependent on labour-market wage rates of both spouses and on the total full income of the household, i.e. the sum of the earning potentials of all its members. According to the unitary model, the household's allocation of expenditures should be invariant with respect to who has the greatest earning potential within the family. This allows testing the income-pooling property in the time allocation context. These effects are estimated with first differences on the following equation.

$$
\Delta L_{i t}^{f}=\beta_{1} \Delta w_{i t}^{f}+\beta_{2} \Delta w_{i t}^{m}+\beta_{3} \Delta y_{i t}^{f}+\beta_{4} \Delta y_{i t}^{m}+\Delta e_{i t}
$$

where $e_{i t}$ is independently and identically distributed across time and individuals. The income-pooling null hypothesis is $H_{0}: \beta_{3}-\beta_{4}=0$.

Table A1 in appendix presents a difference-GMM estimation of Equation (4.1). Specification tests are in-line with what we could expect. The residual appears AR(1) but not $\operatorname{AR}(2)$, and the Hansen test does not reject the overidentification restrictions when the matrix of instruments is composed of first lagged income variables at each period of time. The first column of Table 1 presents the income-pooling test in the absence of domestic production, measuring leisure time as total non-labour market time. 
The second column controls for the presence of household production and 'pure leisure' is total time minus labour and housework time. In both cases, the income-pooling property is rejected at the $5 \%$ level $^{9}$. An increase in females' non-labour income would imply a greater shift upwards in their leisure time than when males' non-labour income increases. The rejection of the income-pooling property is due to the increase in female's bargaining power because her non-labour income unilateraly increases, if leisure time is a normal good. Note that this rejection comes from a specification that may not be flexible enough because non labour income only enters linearly into the demand for leisure. Moreover the division bias may also affect the results. Stronger rejection of the income-pooling for the UK may be found in the literature (e.g. Lundberg, Pollak and Wales, 1997).

We may now turn to examine collective rationality and identify the sharing rule.

\subsection{Demand for leisure}

\section{[INSERT TABLE3]}

Table 2 shows the results of the first-difference estimation of female leisure demand (3.6). The first column (Model I) shows the estimates in the absence of domestic production whereas the second column (Model II) controls for housework. Instruments finally selected are the second lag of public expenditures and of time the woman spends at housework, the first lagged level of non labour income and, the first lag of wages and income for both spouses interacted with the cohabitational dummy. This corresponds to the case in which housework and pure leisure time is endogenous whereas other variables are predetermined. Hansen overidentifying statistics (30.86 for Model 1 and 43.98 for Model 2, with respectively 33 and 46 degrees of freedom for the $\chi^{2}$ distribution) do not reject the validity of the overidentying restrictions. For the first model, including

\footnotetext{
${ }^{9}$ In the case of married women, the imperfect observation of individual non-labour income does not allow to reject the income-pooling property. A precise modelisation of the tax system would probably give better results.
} 
first lagged levels of public expenditures leads to a rejection of the overidentification restrictions (the J-statistic is 114.5 with 62 degrees of fredom), this rejects the predetermination of public expenditures in favour of endogeneity. The Arellano and Bond (1991) specification test gives indications that this choice of instruments is correct, the residual appears autoregressive of order 1 but not of order 2 .

Table A2 in the Appendix shows the Within estimation which corresponds to the case of strict exogeneity of all the covariates. A simple test of the validity of the strict exogeneity assumption consists in including future values of covariates and testing their joint significance with a Wald test. This leads to a clear rejection of the strict exogeneity assumption and justifies the approach in first difference. Compared to the exogenous case, the first-difference model in Table 2 presents estimates that tend to be less significant but corrects the endogeneity bias of income variables with some success. As a price to pay, estimators present a higher variance. Joint significance F-tests realised on the instrumental regressions indicate that first lagged values are strongly correlated with first differences. This is less the case for public expenditures and private expenditures which are weakly correlated to their second lagged level, but remain correlated to first lags of other variables, especially the non labour incomes. Despite the fact that the specification is not rejected, we still have to investigate the assumption of absence of contemporaneous correlation between income variables and leisure demand. This case can be tested by including only second lagged values in the instrumental matrix. Such a model performs relatively well according to specification tests (e.g. the Hansen statistic leads to a p-value of 0.146). Testing the validity of adding a first lag to the first lag in the instrumental matrix leads to a difference Hansen statistic equals to 30.34 (32 degrees of freedom) which does not reject the additional overidentifying restrictions. However testing the validity of adding a first lag to the second lag in the instrumental matrix leads to a difference Hansen statistic equals to 40.74 (28 degrees of freedom). This rejects at the $10 \%$ level the specification with only the second lag in Model I. For the second model, including second lags in the instrumental matrix 
directly leads to a rejection of the overidentifying restrictions (the J-statistic equals to 99.29 with 68 degrees of freedom when both lags are included). Finally, the first model presents the same instrumental matrix than the second, excluding public expenditures and housework. Results concerning the choice of lags (endogeneity versus predetermination) should be taken carefully because second lags tend to be weakly correlated with first differences which may cause a lack of power for the Hansen test.

The $\beta$ coefficient appears to be 0.34 in the first model and 0.38 in the second. This means that a $10 £$ increase in weekly private expenditures raises consumption of leisure by a 3.5 hours. The effect is smaller in the exogenous case. The Slutsky condition, which implies that the $\beta$ coefficient is between 0 and 1 , is not rejected.

The separability assumption should imply that the effect of non-labour income should be the same on leisure demand as on public expenditures, with the sign reversed. When we re-estimated the model after pooling non-labour incomes for both couples, we obtain that the effect of pooled non-labour income is $-0.07(0.018)$ and the effect of public expenditures is $-0.3377(0.1289)$. The null hypothesis implies that the effect of non-labour income plus public expenditures equals zero. Wald statistic appears equal to 8.89 , which clearly rejects the null hypothesis. This negative result could be partly explained by mismeasurements of $G$, due to the omission of consumption inputs in the household production function, for example. In any case, this casts some doubt on the validity of the separability assumption between private consumption and public consumption in household time allocation analysis.

\subsection{Sharing rule}

\section{[INSERT TABLE3]}

Table 3 presents the parameters of the sharing rule specified in Equation (3.5). Females' private expenditures increase considerably with their wages, whereas they only increase very slightly with their partners' wages. This is due to a general increase in the household's full income, but probably not in bargaining power. The effect of 
non-labour income does not appear significant which could be due to mismeasurements of individualised non labour incomes. An increase in households' public expenditures naturally decreases females' shares of private expenditures. According to the separability assumption, this should only be due to income effects and has nothing to do with changes in preferences.

\section{[INSERT TABLE4]}

Table 4 presents prediction of the sharing rule (Table 4) when omitting household production (first column, Model I) and when controling for housework (second column, Model II). The third column corresponds to a simulation in the absence of intrahousehold wage gap. The 'good' prediction should come from Model II. It indicates that a working woman in a two-earner couple gets on average $40 \%$ of household's private expenditures with $10 \%$ of standard deviation. A positive aspect of this prediction is that the sharing rule lies between 0 and 1 without needing to be imposed. Another plus is that the share does not appear unduly unequal between males and females within the family. According to Model 2, extreme sharing arrangements tend to be rare, as only $5 \%$ of the couples are below the sharing rule $22 \%$.

\section{[INSERT FIGURE1]}

The first column of Table 4 predicts the sharing rule when household production is omitted. Regressions, are run on non-labour market time rather than pure leisure. When omitting household production, the distribution of the sharing rule appears centred 6-7\% above the unbiased one. Figure 1 illustrates this fact. Inequality appears greater. The standard error and the difference between the last and first quartile slightly increases. The figure clearly shows that the female's predicted share based on non-labour time statistically dominates the female's predicted share based on pure leisure time. The direction of the bias is as expected: omitting time leads to an overestimation of females' share of welfare. The median of the sharing rule is $47 \%$ for the female, which is more than what we obtained by using only pure leisure time (40\%). The bias is not that 
huge, but could possibly be underestimated in these data because time spent at housework is subjective. Another problem in the model and the data is that time spent at housework only partially includes time spent with children, because a part of the time spent with children is declared as leisure by women. In this case, the complementarity between spouses' time can only be partially controlled.

As a comparison, Table A3 in Appendix shows the results of the sharing rule prediction in the strict exogeneity case. It appears 5 points greater which gives us an idea of the potential small sample bias that can occur in this evaluation. The evaluation of the household production omission bias remains $7 \%$ in the exogenous case.

The third column of Table 4 simulates the distribution of the sharing rule in the absence of an intra-household wage gap. Not surprisingly, the distribution of the sharing rule is more equal. The average sharing rule appears $4 \%$ greater and reaches nearly $45 \%$. The standard deviation becomes really low. In our case, the intra-household wage gap explains around $80 \%$ of the variation in the level of the sharing rule. This illustrates that wage equality is still a big issue from a gender equality perspective, between and also within households.

\section{Conclusion}

A collective demand for leisure is modelled for a sample of British women who are in a couple or single, observed over a period not exceeding 9 years, from 1992 to 2000. A public domestic good can be produced with time spent at housework by family members. Private goods are assumed efficiently allocated conditional on public consumption. First-difference panel data estimates are generated on a sample of 2000 individuals from the BHPS. Women who change family status from single to couple or from couple to single are used to predict the woman's share of income and to determine its distribution for working women in a couple in the U.K. Our results suggest that females' shares of household income tend to be $40 \%$ on average. A prediction bias ignoring household production would lead to an overestimation of nearly 7 points. The 
effect of the intra-household wage gap appears huge and explain most of the variation of the sharing rule. The results should be treated with caution, as theoretical assumptions underlying the results remain strong. In particular, the separability assumption between public and private consumption is rather strong and should be relaxed in fu-

ture research. Furthermore, the results remain conditional on the couples decision to participate into labour and housework activities. Finally, further over-identification restrictions induced by male's behaviour could probably be included in this model in order to improve the identification of the sharing rule.

\section{References}

[1] Apps, P.F. (2003), "Gender, time use and models of the household", IZA Discussion paper

[2] Apps, P.F. and R. Rees (1997), "Collective labor Supply and Household Production", Journal of Political Economy, 105, 178-190

[3] Arellano, M. and S. Bond (1991), "Some tests of specification for panel data: Monte Carlo evidence and an application to employment equations", Review of Economic Studies, 58, 277-297

[4] Aronsson, T., Daunfeldt S.-O. and M. Wikström (2001), "Estimating IntraHousehold Allocation in a collective Model With Household Production", Journal of Population Economics, 14, 569-584

[5] Becker, G. (1981) A Treatise of the Family, Cambridgen Mass. : Harvard University Press

[6] Blundell, R., P.-A. Chiappori, T. Magnac and C. Meghir (2001), "Collective Labour Supply : Heterogeneity and Non-participation", IFS Working Paper 01/19 
[7] Bond, S.R. (2002), "Dynamic panel data models: a guide to micro data and practice", Portuguese Economic Journal, 1, 141-162

[8] Browning, M. and P.-A. Chiappori (1998), "Efficient Intra-Household Allocations : a General Characterization and Empirical Tests", Econometrica, 66, 1241-1278

[9] Browning, M., P.-A. Chiappori and A. Lewbel (2003), "Estimating consumption economies of scale, adult equivalence scales, and household bargaining power", CAM, University of Copenhagen, Working Paper 2003/12

[10] Chiappori, P.-A. (1988), "Rational Household Labor Supply", Econometrica, 56, 63-89.

[11] Chiappori, P.-A. (1992), "Collective Labor Supply and Welfare", Journal of Political Economy, 100, 437-467

[12] Chiappori, P.-A. (1997), "Introducing Household Production in Collective Models of Labor Supply", Journal of Political Economy, 105, 191-209

[13] Chiappori, P.-A., R. Blundell and C. Meghir (2002), "Collective Labour Supply with Children". IFS Working Paper 02/08

[14] Chiappori P.-A., B. Fortin and G. Lacroix (2002), "Marriage market, divorce legislation and household labor supply", Journal of Political Economy, 110, 37-72

[15] Chiappori, P.-A. and I. Ekeland (2002a), "The micro economics of group behavior : General Characterization", mimeo

[16] Chiappori, P.-A. and I. Ekeland (2002b), "The micro economics of group behavior : identification", mimeo

[17] Crouchley, R., S. Bradley and R. Oskrochi (2005), "The impact of sample attrition on employment participation and wages: Evidence from the BHPS", Lancaster University, Working Paper 
[18] Dauphin, A. and B. Fortin (2001), "A test of collective rationality for multi-person households", Economics Letters, 71, 211-216

[19] Donni, O. (2003), "Collective household labor supply: nonparticipation and income taxation", Journal of Public Economics, 87, 1179-1198

[20] Fong, Y-F. and J. Zhang (2001), "The identification of unobservable independent and spousal leisure", Journal of Political Economics, 109, 191-202

[21] Fortin, B and G. Lacroix (1997), "A test of the unitary and collective model of household labour supply", Economic Journal, 107, 933-955

[22] Haddad, L. and R. Kanbur (1991), "How serious is the neglect of intra-household inequality?", Economic Journal, 100, 866-881

[23] Laisney F. (2002), "Welfare analysis of fiscal and social security reforms in Europe: does the representation of the family decision process matter?", final Report on EU-project VS/2000/0778, Mannheim, ZEW

[24] Lise, J. and S. Seitz (2004), "Consumption inequality and intra-household allocations", Queens IER Working paper

[25] Lunberg, S., R. Pollak and T. Wales (1997), "Do husbands and wives pool their resources: Evidence from the United Kingdom child benefit", Journal of Human Resources, 32, 463-480

[26] Vermeulen, F. (2005) "A collective model for female labour supply with nonparticipation and taxation", forthcoming in Journal of Population Economics

[27] Wooldrige, J.M. (2001) "Econometric analysis of cross section and panel data", MIT Press, London. 
Table 1: Data description, BHPS 1992 to $2000^{(*)}$

\begin{tabular}{rccc}
\hline Descriptive statistics & Single women & Women in couple & Men in couple \\
\hline Usual weekly hours of work & 33.88 & 32.48 & 45.10 \\
declared (incl. overtime) & $(13.19)$ & $(12.36)$ & $(9.50)$ \\
Weekly hours of housework & 11.33 & 14.60 & 5.65 \\
& $(8.46)$ & $(9.47)$ & $(4.52)$ \\
Weekly Hours of Leisure & 122.79 & 120.92 & 117.25 \\
& $(12.65)$ & $(11.98)$ & $(10.06)$ \\
Net hourly wage rate & 4.55 & 4.43 & 5.34 \\
& $(2.39)$ & $(2.2 .28)$ & $(2.80)$ \\
& 41.12 & 15.75 & 9.86 \\
Non labour weekly income & $(55.71)$ & $(27.03)$ & $(33.52)$ \\
& 806.36 & 760.18 & 907.36 \\
Full Income per week & $(400.72)$ & $(385.49)$ & $(474.66)$ \\
& 0.36 & 0.52 & 0.52 \\
Presence of a Child & $(0.48)$ & $(0.50)$ & $(0.50)$ \\
& & 0.76 & 0.76 \\
Married Couple & & $(0.42)$ & $(0.42)$ \\
& 2585 & 7179 & 7179 \\
\hline
\end{tabular}

${ }^{(*)}$ Standard errors are in parenthesis.

Table 2: Female's leisure demand ${ }^{(*)}$

\begin{tabular}{|c|c|c|c|c|}
\hline & \multicolumn{2}{|c|}{$\begin{array}{l}\text { Non labour market time } \\
\text { (I) }\end{array}$} & \multicolumn{2}{|c|}{$\begin{array}{l}\text { Pure leisure time } \\
\text { (II) }\end{array}$} \\
\hline & Parameter & Standard error & Parameter & Standard error \\
\hline $1 / w_{f}$ & -5.3383 & $(22.220)$ & -1.2611 & $(21.239)$ \\
\hline$(1-d) \times$ private expenditures $/ w_{f}$ & 0.3457 & $(0.1334) * * *$ & 0.3830 & $(0.1522) * *$ \\
\hline$d / w_{f}$ & 27.062 & $(23.456)$ & 28.794 & $(22.240)$ \\
\hline$d$ & 54.375 & $(25.347) * *$ & 56.474 & $(27.456) * *$ \\
\hline$d \times$ husband's wage $/ w_{f}$ & -3.2391 & $(1.0230)^{* * *}$ & -1.8614 & $(1.3083)$ \\
\hline$d \times$ female's non labour income $/ w_{f}$ & -0.0624 & $(0.0409)$ & -0.1105 & $(0.0492) * *$ \\
\hline$d \times$ husband's non labour income $/ w_{f}$ & -0.0334 & $(0.0305)$ & -0.0333 & $(0.0383)$ \\
\hline$d \times$ public expenditures $/ w_{f}$ & & & -0.3235 & $(0.1210) * * *$ \\
\hline & Statistic & p-value & Statistic & p-value \\
\hline $\mathrm{AR}(1)-\mathrm{z}$ stat & -4.43 & 0.000 & -6.08 & 0.000 \\
\hline $\mathrm{AR}(2)-\mathrm{z}$ stat & -0.31 & 0.759 & -0.43 & 0.670 \\
\hline J-test & 30.86 & 0.574 & 43.98 & 0.557 \\
\hline Number of instruments & 40 & & 54 & \\
\hline Number of individuals & 2182 & & 2182 & \\
\hline Number of observations & 6538 & & 6538 & \\
\hline
\end{tabular}

${ }^{(*)}$ Difference-GMM estimator. Variance covariance matrix is robust to heteroscedasticity and autocorrelation. Income variables are predetermined. $d$ is the cohabitation status variable whereas $w$ is the hourly net wage rate. One, two and three stars represent respectively $0.1,0.05$ and 0.01 level of significance. 
Table 3: Sharing rule ${ }^{(*)}$

\begin{tabular}{rllll}
\hline Female's level of private expenditures & \multicolumn{2}{c}{ Non labour market time } & \multicolumn{2}{c}{$\begin{array}{c}\text { Pure leisure time } \\
\text { (II) }\end{array}$} \\
\hline Constant & 78.271 & $(66.117)$ & 75.185 & $(58.673)$ \\
Female's wage rate & 157.27 & $(25.508) * * *$ & 147.46 & $(24.347) * * *$ \\
Husband's wage rate & -9.3686 & $(4.5405) * *$ & -4.8605 & $(3.9693)$ \\
Female's non labour income & -0.1806 & $(0.1418)$ & -0.2886 & $(0.1757)$ \\
Husband's non labour income & -0.0967 & $(0.0994)$ & -0.0870 & $(0.1083)$ \\
Public expenditures & & & -0.8447 & $(0.4601)^{*}$ \\
\hline
\end{tabular}

${ }^{(*)}$ See Table3.

Table 4: Quantiles of the predicted female's share of private expenditure

\begin{tabular}{lccc}
\hline & $\begin{array}{c}\text { Non labour market time } \\
(\mathrm{I})\end{array}$ & $\begin{array}{c}\text { Pure leisure } \\
(\mathrm{II})\end{array}$ & Without wage gap $^{(*)}$ \\
\hline $5 \%$ & 0.2732 & 0.2237 & 0.3969 \\
$10 \%$ & 0.3209 & 0.2677 & 0.4109 \\
$25 \%$ & 0.3949 & 0.3364 & 0.4288 \\
$50 \%$ & 0.4698 & 0.4026 & 0.4432 \\
$75 \%$ & 0.5400 & 0.4665 & 0.4579 \\
$90 \%$ & 0.6065 & 0.5264 & 0.4713 \\
$95 \%$ & 0.6530 & 0.6423 & 0.4790 \\
\hline Mean & 0.4668 & 0.3999 & 0.4415 \\
Standard Error & 0.1166 & 0.1032 & 0.0262 \\
Q75-Q25 & 0.1451 & 0.1301 & 0.0291 \\
\hline
\end{tabular}

(*) Equal wage rates between spouses are imposed, household full income and parameters are left unchanged (II).

Figure 1: Distribution of female's ratio of household's private expenditures

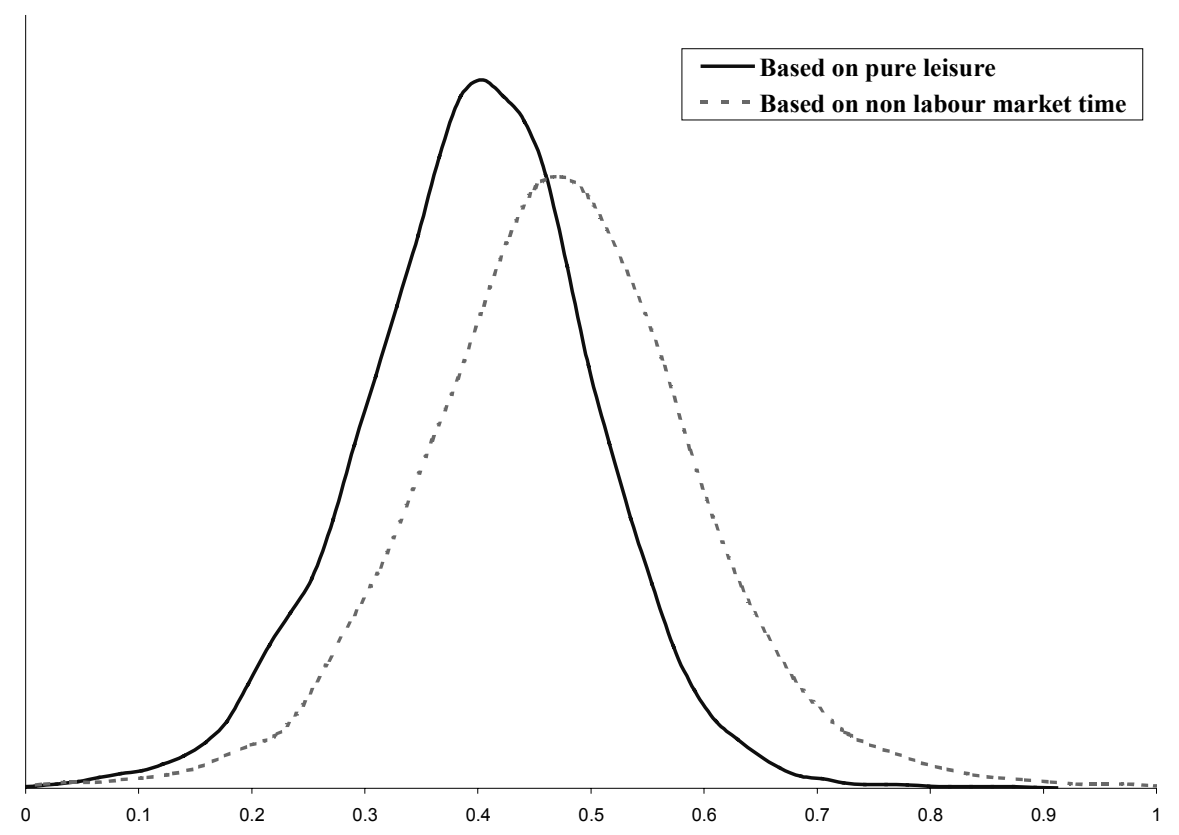


APPENDIX

\section{Table A1: Income-pooling test ${ }^{(*)}$}

\begin{tabular}{lclcl}
\hline Leisure demand & \multicolumn{2}{c}{ Total non-labour market time } & \multicolumn{2}{c}{ Pure leisure time } \\
& Parameter & Standard error & Parameter & Standard error \\
\hline Own wage & 0.3265 & $(0.1185) * * *$ & 0.4201 & $(0.1594) * * *$ \\
Spouse's wage & -0.0679 & $(0.1915)$ & 0.2452 & $(0.2665)$ \\
Own non labour income & 0.0488 & $(0.0198) * *$ & 0.0723 & $(0.0271)^{* * *}$ \\
Spouse's non labour income & -0.0064 & $(0.0144)$ & 0.0082 & $(0.0143)$ \\
& & & & \\
\hline & Statistic & p-value & Statistic & p-value \\
AR(1) - z stat & -3.03 & 0.002 & -5.05 & 0.000 \\
AR(2) - z stat & 0.74 & 0.461 & 0.88 & 0.378 \\
J-test $\chi^{2}(32)$ & 37.6 & 0.106 & 33.5 & 0.218 \\
Income pooling - t test & 5.25 & 0.022 & 5.02 & 0.025 \\
\hline
\end{tabular}

${ }^{(*)}$ Difference-GMM estimator. Variance-covariance matrix is robust to heteroscedasticity and autocorrelation. Income variables are predetermined and instrumented by their first lag in level. Time is in hours per week, non-labour income is expressed in pounds per week. Wage is the after tax wage rate. Dual earner unmarried couples (942 observations).

Table A2: Female's Leisure demand, strict exogeneity case ${ }^{(*)}$

\begin{tabular}{|c|c|c|c|c|}
\hline & \multicolumn{2}{|c|}{$\begin{array}{l}\text { Non labour market time } \\
\text { (I) }\end{array}$} & \multicolumn{2}{|c|}{$\begin{array}{l}\text { Pure leisure time } \\
\text { (II) }\end{array}$} \\
\hline & Parameter & $\begin{array}{c}\begin{array}{c}\text { Standard } \\
\text { error }\end{array} \\
\end{array}$ & Parameter & Standard error \\
\hline $1 / w_{f}$ & -10.759 & $(22.220) * * *$ & -17.670 & $(1.1790) * * *$ \\
\hline$(1-d) \times$ private expenditures $/ w_{f}$ & 0.1203 & $(0.0132) * * *$ & 0.2231 & $(0.1325) * * *$ \\
\hline$d / w_{f}$ & -8.7123 & $(1.7872) * * *$ & 2.4489 & $(1.8673)$ \\
\hline$d$ & 23.141 & $(2.2212) * * *$ & 41.314 & $(2.1140) * * *$ \\
\hline$d \times$ husband's wage $/ w_{f}$ & 0.7134 & $(0.1856) * * *$ & 2.5365 & $(0.2035) * * *$ \\
\hline$d \times$ female's non labour income $/ w f$ & 0.1096 & $(0.0145)$ & 0.0964 & $(0.0154) * * *$ \\
\hline$d \times$ husband's non labour income $/ w_{f}$ & -0.0201 & $(0.0155) * * *$ & -0.0392 & $(0.0165) * *$ \\
\hline$d \times$ public expenditures $/ w_{f}$ & & & -0.4499 & $(0.0119) * * *$ \\
\hline Strict exogeneity F-test (p-value) & 0.0002 & & 0.0007 & \\
\hline Number of individuals & 2342 & & 2342 & \\
\hline Number of observations & 9764 & & 9764 & \\
\hline
\end{tabular}

${ }^{(*)}$ Fixed-effect estimator. Income variables are strictly exogenous. $d$ is the cohabitation status variable whereas $w$ is the hourly net wage rate. One, two and three stars represent respectively $0.1,0.05$ and 0.01 level of significance. The strict exogeneity test is a test of joint significance of future variables $(t+1)$ when added to the model (see Wooldrige, 2001, p.285) 
Table A3: Sharing rule, strict exogeneity case ${ }^{(*)}$

\begin{tabular}{rllll}
\hline Female's level of private expenditures & \multicolumn{2}{c}{$\begin{array}{c}\text { Non labour market time } \\
\text { (I) }\end{array}$} & \multicolumn{2}{c}{$\begin{array}{c}\text { Pure leisure time } \\
\text { (II) }\end{array}$} \\
\hline Constant & -72.446 & $(19.854)^{* * *}$ & 10.976 & $(8.1070)$ \\
Female's wage rate & 192.42 & $(5.4525)^{* * *}$ & 185.17 & $(3.2478)^{* * *}$ \\
Husband's wage rate & 5.9326 & $(1.6695)^{* * *}$ & 11.369 & $(1.1255)^{* * *}$ \\
Female's non labour income & 0.9116 & $(0.1547)^{* * *}$ & 0.4320 & $(0.0733)^{* * *}$ \\
Husband's non labour income & -0.1676 & $(0.1302)$ & -0.1757 & $(0.0747)^{* *}$ \\
Public expenditures & & & -2.0162 & $(0.1310)^{* * *}$ \\
\hline Mean predicted share & 0.5227 & $(0.1279)$ & 0.4525 & $(0.1203)$ \\
\hline (in \% of household expenditures) & & & &
\end{tabular}

${ }^{(*)}$ See Table A2. 